\title{
First North American occurrences of Qiupalong (Theropoda: Ornithomimidae) and the palaeobiogeography of derived ornithomimids
}

\author{
Bradley McFeeters $^{\mathrm{a} \star}$, Michael J. Ryan ${ }^{\mathrm{ab}}$, Claudia Schröder-Adams ${ }^{\mathrm{a}}$, and Philip J. Currie ${ }^{\mathrm{c}}$ \\ ${ }^{a}$ Department of Earth Sciences, Carleton University, 1125 Colonel By Drive, Ottawa, ON K1S 5B6, \\ Canada; ${ }^{\mathrm{b} C l e v e l a n d}$ Museum of Natural History, 1 Wade Oval Drive, University Circle, Cleveland, \\ $\mathrm{OH}$ 41106-1767, USA; 'Department of Biological Sciences, University of Alberta, Edmonton, \\ AB T6G 2E9, Canada \\ *bradleymcfeeters@cmail.carleton.ca
}

\section{OPEN ACCESS}

Citation: McFeeters B, Ryan MJ, SchröderAdams C, and Currie PJ. 2017. First North American occurrences of Qiupalong (Theropoda: Ornithomimidae) and the palaeobiogeography of derived ornithomimids. FACETS 2: 355-373. doi: | 0.1 | 39/facets-20 | 6-0074

Editor: David C. Evans

Received: December 8, 2016

Accepted: March 12, 2017

Published: April 20, 2017

Copyright: (c) 2017 McFeeters et al. This work is licensed under a Creative Commons Attribution 4.0 International License (CC BY 4.0), which permits unrestricted use, distribution, and reproduction in any medium, provided the original author(s) and source are credited.

Published by: Canadian Science Publishing

\begin{abstract}
Ornithomimid material from the Belly River Group (Campanian) of Alberta, Canada is described as sharing characters with Qiupalong henanensis from the Qiupa Formation of Henan Province, China. Derived characters and character combinations of the pubis and astragalocalcaneum were previously used to diagnose Q. henanensis and support the referral of this material to Qiupalong sp., representing the first known occurrences of Qiupalong outside of China. Qiupalong is the sixth ornithomimid taxon to be reported from the Dinosaur Park Formation and the first ornithomimid genus with a transcontinental distribution. The Alberta material represents the oldest known occurrences of Qiupalong, and a reconsideration of character evidence suggests that this genus is phylogenetically nested within other North American ornithomimids. A North American origin for Qiupalong and subsequent dispersal to Asia is proposed.
\end{abstract}

Key words: Cretaceous, Dinosauria, palaeobiogeography, Ornithomimidae, Dinosaur Park Formation

\section{Introduction}

Definitive records of Ornithomimidae have been described exclusively from Upper Cretaceous deposits of Asia and North America, and are best represented in the Western Interior of Canada and the United States, and the Gobi Desert region of Mongolia and northern China (Makovicky et al. 2004). Phylogenetic and palaeobiogeographic analyses of Ornithomimosauria by Kobayashi and Barsbold (2004) supported an Asian origin for Ornithomimidae and a single dispersal of ornithomimids from Asia into North America during, or prior to, the Campanian. Although it is widely accepted that dispersal played a key role in the palaeobiogeographic history of Ornithomimidae (Ji et al. 2003; Kobayashi and Barsbold 2004; Makovicky et al. 2004; Prieto-Márquez 2010), no ornithomimosaur genus has been demonstrated to have a transcontinental distribution. Gilmore (1933) described the first known Asian ornithomimid as Ornithomimus asiaticus, considering it congeneric with ornithomimids known from North America. Russell (1972) recognized "O." asiaticus as a more basal member of Ornithomimidae and made it the type species of the new genus Archaeornithomimus, an assessment supported by recent phylogenetic analyses (Xu et al. 2011; Sues and Averianov 2016). Russell (1972) considered Archaeornithomimus to be present in both Asia and North America, but 
a revision of this taxon by Smith and Galton (1990) removed the North American material from Ornithomimidae.

Xu et al. (2011) described a new genus and species of Asian ornithomimid, Qiupalong henanensis, on the basis of a single occurrence (HGM 41HIII-0106) from the Qiupa Formation of Luanchuan County, Henan Province, China. Xu et al. $(2011,214)$ diagnosed Q. henanensis as an "ornithomimid theropod dinosaur with unique features (a notch on the lateral surface of the medial [sic] posterior process of the proximal end of tibia and a small pit is present at the contact between astragalus and calcaneum) as well as a combination of primitive (short anterior extension of pubic boot) and derived features (arctometatarsal condition, straight pubic shaft, and wide angle between pubic shaft and boot)". In addition to the short anterior extension of the pubic boot (character 43: state 0 ), the ventrally curved pedal ungual (character 47: state 0 ) of $Q$. henanensis also optimizes as a locally autapomorphic reversal in the phylogenetic analysis conducted by Xu et al. (2011). The plesiomorphic states for both of these characters were scored as occurring otherwise only in non-ornithomimid theropods, whereas Qiupalong was recovered deeply nested in Ornithomimidae as the sister taxon of the previously identified North American ornithomimid clade (Kobayashi and Lü 2003; Xu et al. 2011).

Material collected from Campanian Belly River Group strata in Dinosaur Provincial Park (Alberta, Canada) allows for the first identification of the characters used to diagnose Qiupalong in ornithomimid material from North America. This material includes a partial postcranial skeleton (CMN 8902) with the diagnostic character combination of a distally straight pubic shaft and a short anterior extension of the pubic boot, and an isolated astragalocalcaneum (UALVP 53595) with the autapomorphic condition of a pit between the astragalus and calcaneum. We also describe an isolated pedal ungual (UALVP 52861) as nearly identical to the corresponding element in Q. henanensis and distinct from previously described curved ornithomimid pedal unguals from Alberta (Longrich 2008). Ornithomimids are among the most common theropods collected in Alberta (Currie and Koppelhus 2015), with a potentially high taxonomic diversity represented. Ornithomimid species previously reported from the Belly River Group in Alberta include Struthiomimus altus (Lambe 1902), Dromiceiomimus samueli (Parks 1928), Ornithomimus edmontonicus (Russell 1972), Rativates evadens (McFeeters et al. 2016), and an unnamed large-bodied ornithomimid (Longrich 2008). However, Makovicky et al. (2004) suggested that D. samueli and O. edmontonicus are synonymous, and Longrich (2008) opted to subsume both under "Ornithomimus sp." when referring to the material from the Belly River Group.

\section{Systematic Palaeontology}

Theropoda Marsh, 1882

Ornithomimosauria Barsbold, 1976

Ornithomimidae Marsh, 1890

Qiupalong Xu et al., 2011

Qiupalong sp.

Referred material: CMN 8902 (partial postcranial skeleton including cervical, dorsal, and caudal vertebrae, ribs, scapulacoracoid, proximal humerus, ulna, ilium, incomplete pubes, proximal femur); UALVP 53595 (astragalocalcaneum).

\section{cf. Qiupalong sp.}

Referred material: UALVP 52861 (pedal ungual)? 
Locality: Belly River Group (Campanian), Dinosaur Provincial Park, Alberta, Canada (Eberth 2005). CMN 8902 was collected in 1921, prior to the establishment of the modern stratigraphic subdivisions of the Belly River Group (Eberth and Hamblin 1993), and the exact locality of this specimen has not been relocated. Field notes by C.M. Sternberg on file at the CMN give the locality as " $1 \frac{112}{2}$ miles $[2.4 \mathrm{~km}]$ east of Little Sandhill Creek. Middle of the beds ... in the shaley clay". This specimen could derive from either the Oldman Formation or the Dinosaur Park Formation. UALVP 53595 was collected from the Dinosaur Park Formation 1 km northwest of Happy Jack's Ferry Crossing in Dinosaur Provincial Park, approximately $20 \mathrm{~m}$ above the contact with the Oldman Formation and $669 \mathrm{~m}$ above sea level. UALVP 52861 was collected from the Dinosaur Park Formation in the core area of Dinosaur Provincial Park, $675 \mathrm{~m}$ above sea level (the contact with the Oldman Formation was not observed at this locality). GPS coordinates for both specimens are on file at the UALVP.

\section{Description}

The following elements display characters supporting the presence of Qiupalong in the Belly River Group. Additional elements of CMN 8902 (vertebrae and partial limbs) are not comparable with the known material of Q. henanensis (HGM 41HIII-0106) but are generally consistent with the previously described morphology of other Ornithomimidae (e.g., Makovicky et al. 2004).

\section{Pubis}

The partial postcranial skeleton CMN 8902 includes broken and incomplete portions of both pubes, with the most substantial portion being the conjoined distal ends of these elements (Fig. 1 and Table 1). The proximal portion of the right pubic shaft is straight and robust (Figs. 1A, 1B). It is wider anteroposteriorly than lateromedially at the proximal end and approximately cylindrical at the distal end (Figs. 1C, 1D). The origin of the pubic apron can be traced from a thin, sharp ridge positioned posteromedially at the posterior end. This ridge follows a weakly sigmoidal curve as it transitions to the anteroposteriorly thicker broken edge of the pubic apron extending medially from the middle of the cylindrical pubic shaft at the distal end of the fragment. In cross section, the junction of the pubic shaft and pubic apron is concave anteriorly and flat posteriorly. The distal portions of the pubic shafts are also robust and cylindrical with the pubic apron extending from the medial surface of the shaft, and are closely appressed for the main distal portion preserved (Figs. 1E-1I). The distal part of the pubic shaft is straight, as in other Canadian ornithomimids and Q. henanensis (Xu et al. 2011). The distal end of the shaft is expanded anteriorly and posteriorly, with the posterior expansion originating more proximally. The distal anterior border of the shaft is gently concave above the pubic boot in lateral view, as in O. edmontonicus (CMN 8632, ROM 851) and S. altus (AMNH 5339, CMN 930), but unlike Q. henanensis (Xu et al. 2011).

The anterior extension of the pubic boot is better preserved on the right pubis. As in Q. henanensis (Xu et al. 2011) the anterior extension is short, not exceeding the anteroposterior width of the pubic shaft in length, and projects more anteriorly than the anterior border of the pubic shaft (Fig. 1G). The obtuse angle between the anterior border of the pubic shaft and the dorsal border of the anterior extension is smaller in CMN 8902 than in Q. henanensis, giving the end of the anterior extension a slightly upturned appearance as in some specimens of O. edmontonicus (AMNH 5201). The anterior extension of the pubic boot is transversely expanded. The anterior extremity of the pubic boot projects laterally. Anteroventrally, the right and left pubes are fused (Fig. 1E). The ventral surface of the pubic boot is flat, rather than cleft as in O. edmontonicus (CMN 8632, ROM 851). In lateral view, the ventral edge of the pubic boot is weakly convex, but the ventral outline is poorly preserved. The posterior extension of the pubic boot is unpreserved. 


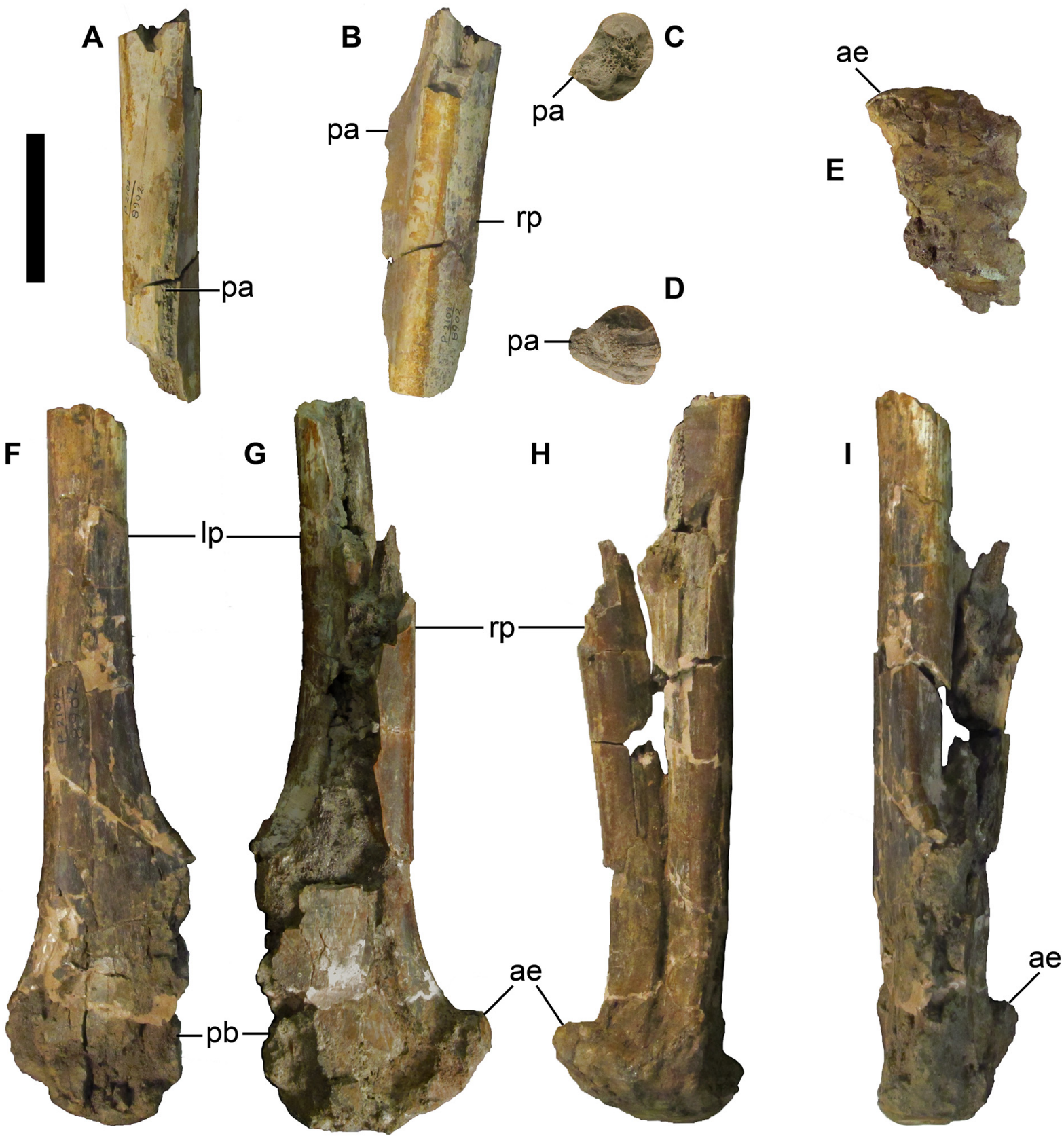

Fig. 1. Pubis of Qiupalong sp., CMN 8902. Proximal fragment of right pubis in (A) medial, (B) posterior, (C) proximal, and (D) distal views. Distal fragment of right and left pubes in (E) distal, (F) left lateral, (G) right lateral, (H) anterior, and (I) posterior views. ae, anterior extension of pubic boot; lp, left pubic shaft; pa, pubic apron; pb, pubic boot; rp, right pubic shaft. Scale bar equals $5 \mathrm{~cm}$.

\section{Astragalocalcaneum}

UALVP 53595 consists of an articulated and partly fused incomplete right astragalus and calcaneum (Fig. 2 and Table 1). As in Q. henanensis (Xu et al. 2011), a deep pit is present anterodorsally along the contact between the astragalus and calcaneum. In UALVP 53595, this pit measures 
Table 1. Measurements of elements described in this study.

Specimen

Dimension

CMN 8902

\begin{tabular}{|lc|}
\hline Pubis, length of figured proximal fragment (Figs. 1A, 1B) & $125^{*}$ \\
\hline Pubis, circumference of figured proximal fragment (Figs. 1C, 1D) & $\sim 80$ \\
\hline Pubis, length of figured distal fragment (Figs. 1E-I) & $228^{*}$ \\
\hline Pubis, anteroposterior length of pubic boot & $65^{\star}$ \\
\hline Pubis, length of anterior extension of pubic boot & 23 \\
\hline Pubis, lateral extent of anterior extension of pubic boot from midline & 30 \\
\hline UALVP 53595 & $37^{*}$ \\
\hline Astragalocalcaneum, maximum width & $43^{*}$ \\
\hline Astragalus, maximum height & $29^{*}$ \\
\hline Astragalus, maximum mediolateral width & $20^{*}$ \\
\hline Astragalus, minimum mediolateral width & 4 \\
\hline Astragalar pit, maximum dimension & 33 \\
\hline Calcaneum, maximum height & 14 \\
\hline Calcaneum, maximum mediolateral width & 27 \\
\hline Calcaneum, maximum anteroposterior length & 18 \\
\hline Pedal ungual, length along dorsal curve & 42 \\
\hline Pedal ungual, length straight & 45 \\
\hline Pedal ungual, height of proximal end & 18 \\
\hline
\end{tabular}

Note: Measurements marked with an asterisk $\left(^{\star}\right)$ are taken from incompletely preserved dimensions.

$3 \mathrm{~mm} \times 4 \mathrm{~mm}$, with the long axis oriented approximately parallel to the anterolateral ridge of the dorsal process of the astragalus. The pit invades the lateral border of the astragalus and is enclosed dorsally by a short bridge of bone that is fused with the calcaneum. Posterior to the bridge and anteroventral to the pit, the externally visible contact between the astragalus and calcaneum is open, but the elements are inseparable as preserved.

The astragalus is incompletely preserved, with the lateral condyle forming the majority of the preserved portion. A prominent anterodorsal ridge connects the broken anterolateral corner of the dorsal process to the fused astragalocalcaneal "bridge" and separates the lateral and anterior faces of the dorsal process. The lateral face of the dorsal process is anteroposteriorly concave, forming a facet for the medial surface of the unpreserved distal fibula, and has an acute posterolateral corner. The boundary between the dorsal process and the lateral condyle can be determined by the more heavily vascularized bone texture near the surface of the latter and is sharply demarcated by a line that crosses the anterodorsal ridge. The straight dorsal border of the lateral condyle descends steeply medially in anterior view. The lateral border of the lateral condyle is deeply notched anteroventrally, to receive an interlocking triangular process of the calcaneum, as in other ornithomimids including Q. henanensis (Xu et al. 2011). The preserved ventral border of the lateral condyle is 

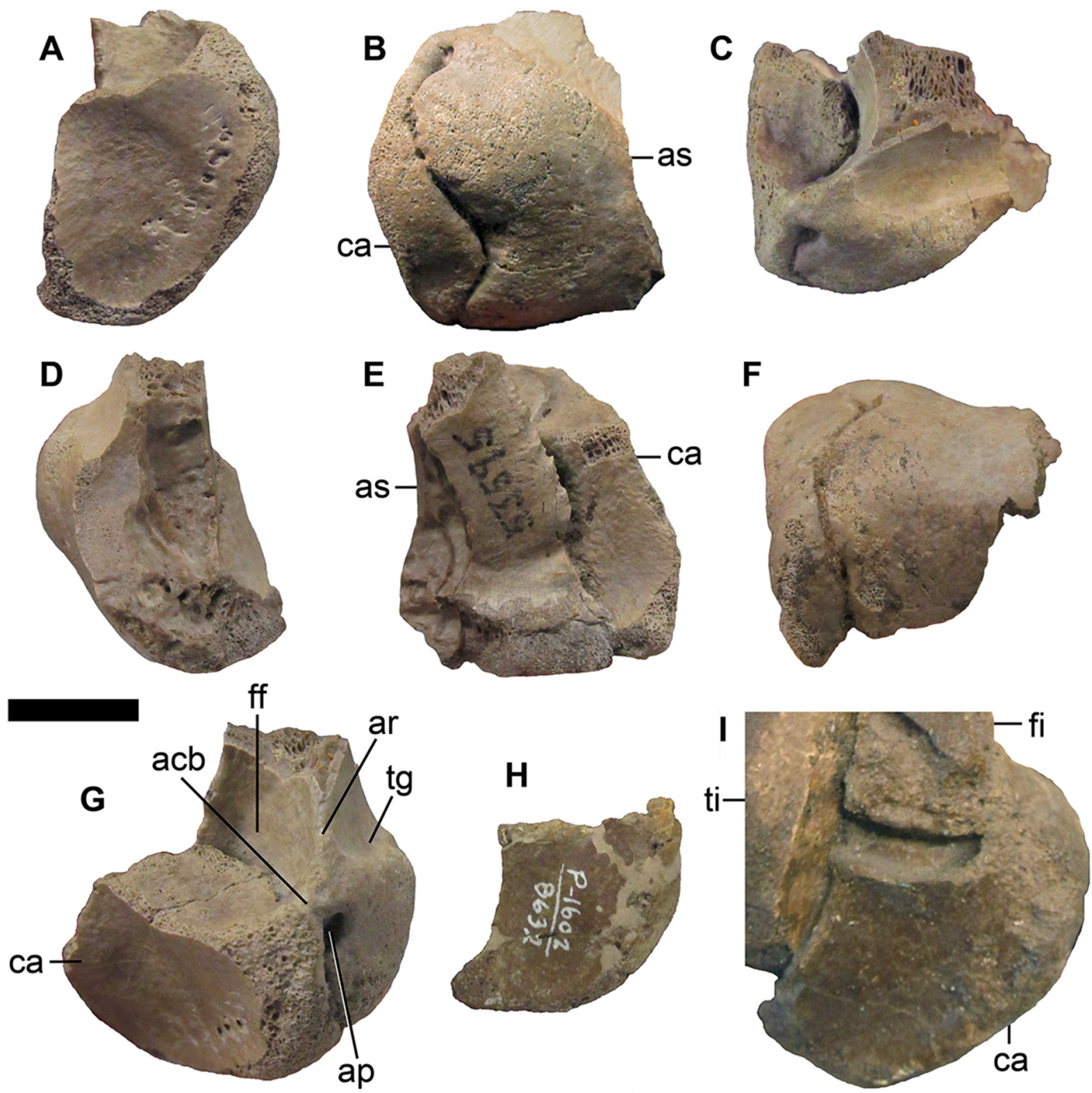

Fig. 2. Right astragalocalcaneum of Qiupalong sp., UALVP 53595 in (A) lateral; (B) anterior; (C) dorsal; (D) medial; (E) posterior; (F) ventral; and (G) oblique dorsolateral view. Right calcaneum of Ornithomimus edmontonicus, CMN 8632 in (H) lateral view. Left calcaneum of Struthiomimus altus, UCMZ 1980.1 in (I) lateral view (reversed). Compare with Q. henanensis, HGM 41HIII-0106 (Xu et al. 2011, fig. 5). acb, astragalocalcaneal bridge; ar, anterodorsal ridge of astragalus; ap, astragalar pit; as, astragalus, ca, calcaneum; ff, fibular facet of astragalus; fi, fibula; ti, tibia; tg, transverse groove of astragalus. Scale bar equals $2 \mathrm{~cm}$.

straight in anterior view (Fig. 2B). The posterior surface of the astragalus is flat and vertical dorsally, and curves posteroventrally around the distal end of the tibia. The astragalus was not fused to the tibia.

The calcaneum is nearly complete, with only minor abrasion to the lateral edges. In lateral view, the calcaneum is nearly identical to that of Q. henanensis (Xu et al. 2011), being much higher dorsoventrally than wide anteroposteriorly. In S. altus (UCMZ 1980.1) and O. edmontonicus (CMN 
8632) the calcaneum is proportionately lower dorsoventrally, relative to its anteroposterior width (Figs. 2H, 2I). The lateral surface of the calcaneum is concave. In posterior view, the facet for articulation with the distal end of the tibia is similar in shape to that of Q. henanensis (Xu et al. 2011), but broader mediolaterally relative to the dorsoventral height (Fig. 2E). The calcaneum has a broad, trapezoidal dorsal surface, likely forming an articular facet for the distal end of the fibula (Fig. 2C). Xu et al. (2011,215) interpreted the contact between the fibula and the ankle in Qiupalong as involving only the astragalus, unlike other ornithomimosaurs. However, the fibula of Q. henanensis is unknown, and the figured astragalus and calcaneum do not appear to greatly differ from UALVP 53595 (or other ornithomimids) in this regard.

\section{Pedal ungual}

UALVP 52861 is an isolated pedal ungual (Fig. 3 and Table 1). The edges of the element are rounded and polished, indicative of fluvial transport (e.g., Mallon and Evans 2014). The relatively wide, symmetrical shape of the proximal articular surface identifies it as the ungual of the third digit (pedal phalanx III-4). The height of the proximal end, including the posterodorsal process, is equal to its width. The posterodorsal process is moderately developed. There is a shallow ovoid depression on
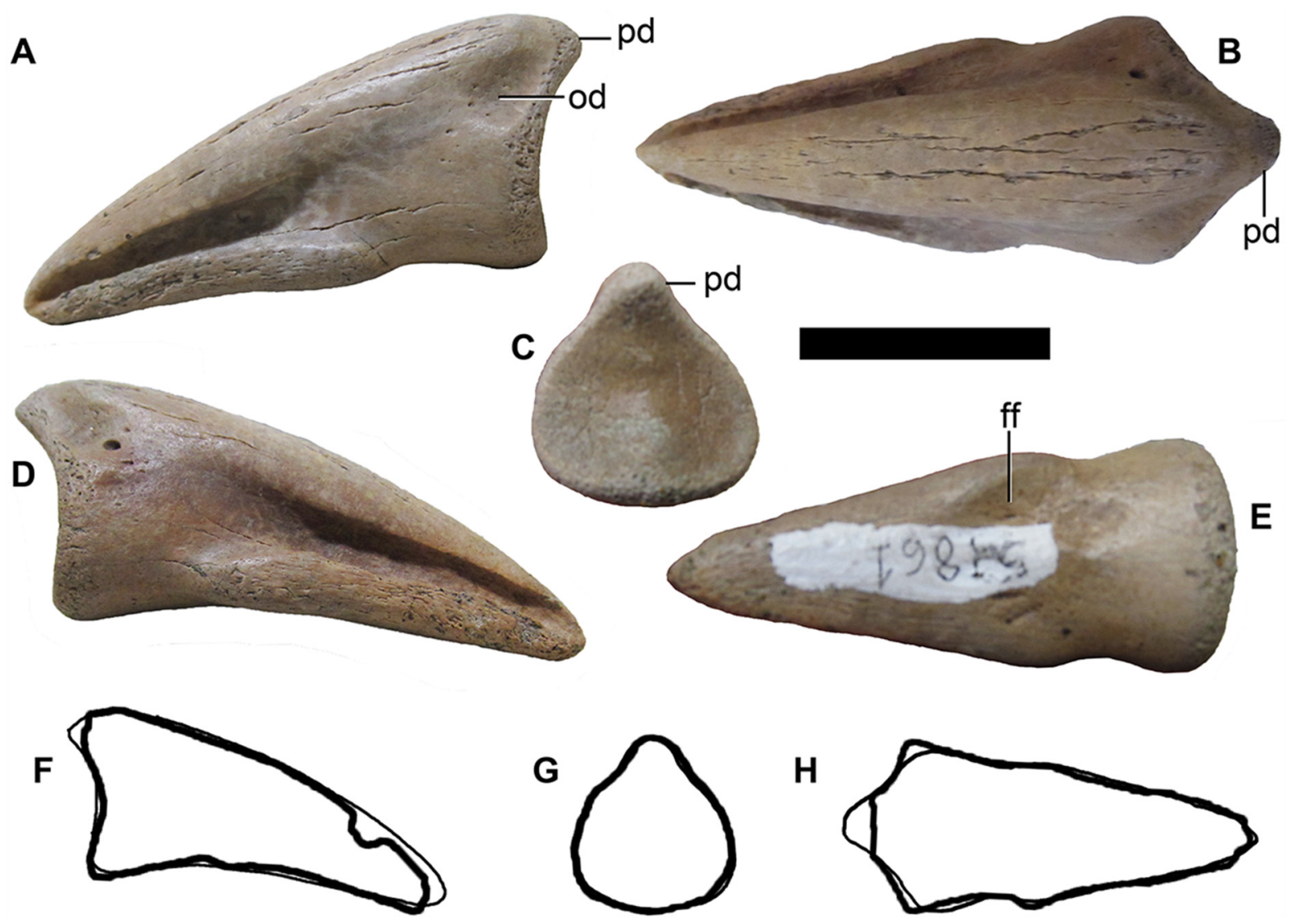

Fig. 3. Pedal ungual III-4 of Ornithomimidae cf. Qiupalong sp., UALVP 52861 in (A) lateral or medial, (B) dorsal, (C) proximal, (D) lateral or medial, and

(E) ventral views. Outline comparison of cf. Qiupalong sp. UALVP 52861 (thin outlines) and Qiupalong henanensis HGM 41 HIII-0106 (heavy outlines) in (F) lateral or medial, (G) proximal, and (H) dorsal views. HGM 41HIII-0106 outlines traced after Xu et al. (2011, fig. 7) and scaled to the same ungual length. $\mathrm{ff}$, flexor fossa; od, ovoid depression; pd, proximodorsal process. Scale bar for A-E equals $2 \mathrm{~cm}$. 
either side of the ungual ventral to the proximodorsal process (Fig. 3A). The proximal part of the ungual is relatively short proximodistally, with medial and lateral borders angled towards each other distally in dorsal and ventral views. The distal part of the ungual is angled ventrally relative to the proximal part and has a straight ventral border in medial and lateral views. The dorsal border of the ungual is convex in medial and lateral views. The ventral surface is flat distally, with a greatly reduced flexor fossa and flexor tubercle proximally (Fig. 3E).

\section{Discussion and Conclusions}

\section{Affinities of the Canadian material}

\section{CMN 8902}

CMN 8902 was previously referred to S. altus by Russell (1972). However, the pubis of CMN 8902 shares the following unique combination of characters with $Q$. henanensis: a very short anterior extension of the pubic boot (Xu et al. 2011, character 43: state 0), a distally straight pubic shaft (Xu et al. 2011, character 44: state 1), and the tip of the anterior extension of the pubic boot extending more anteriorly than the anterior border of the shaft (Xu et al. 2011, character 46: state 1) (Fig. 4A; Xu et al. 2011, figs. 3 and 8). In other Canadian ornithomimids, including specimens of S. altus (AMNH 5339, UCMZ 1980.1) and O. edmontonicus (CMN 8632, ROM 851, TMP 1995.110.0001), the anterior extension of the pubic boot is more elongate (Xu et al. 2011, character 43: state 1) (Figs. 4C-4F). The pubic boot is incompletely preserved in the holotype of S. altus (CMN 930), but enough of the anterior extension is present to indicate that it was larger in that specimen than in CMN 8902 (Fig. 4B). It is unlikely that this character is strongly influenced by ontogeny, because the proportions of the pubic boot are relatively conservative in the ontogenetic series of Gallimimus bullatus (Osmólska et al. 1972, pl. 46 and 50; Xu et al. 2011, fig. 8), and CMN 8902 is similar in size to other larger ornithomimid specimens from the Belly River Group (Russell 1972). Therefore, we interpret the reduced anterior extension of the pubic boot as a shared derived character uniting CMN 8902 and Q. henanensis.
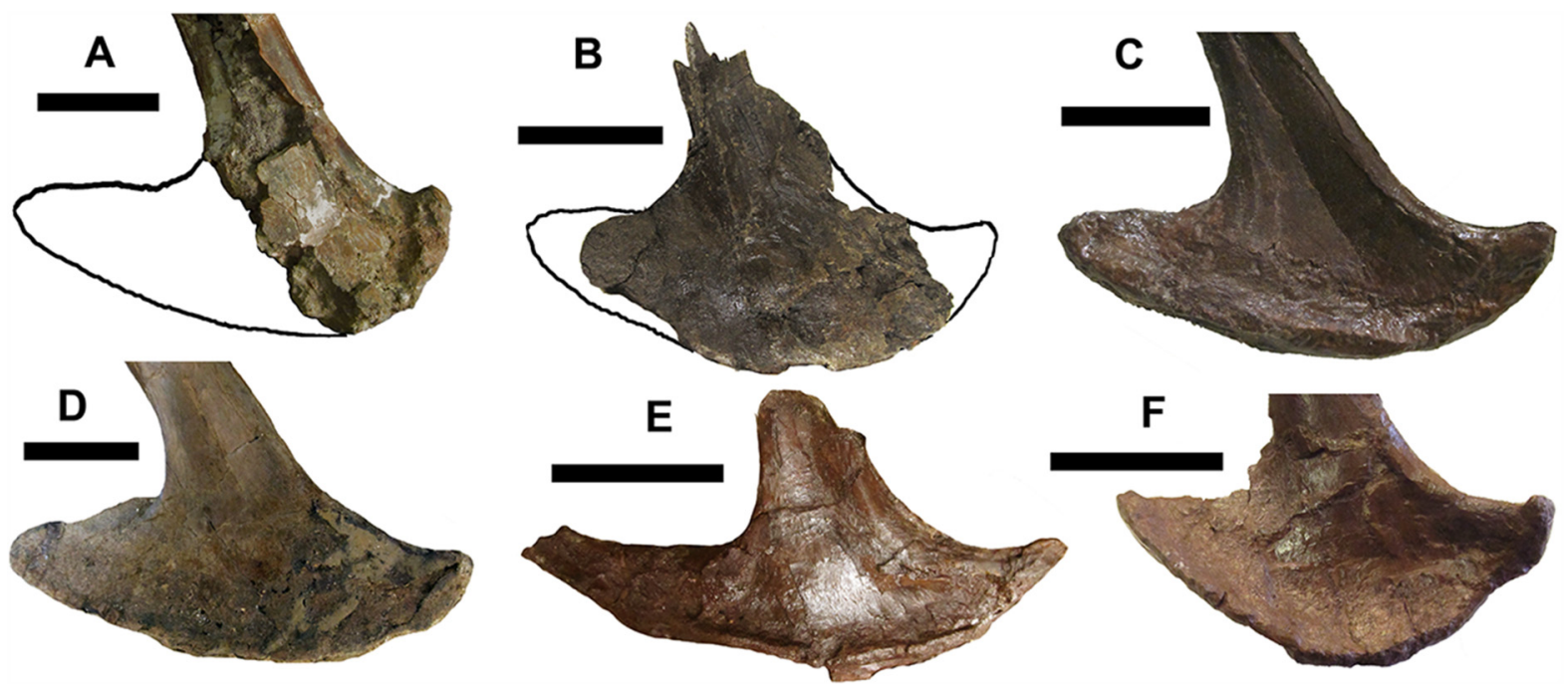

Fig. 4. Pubic boots of Ornithomimidae in right lateral view. (A) Qiupalong sp., CMN 8902; (B) Struthiomimus altus, CMN 930; (C) S. altus, AMNH 5339 (reversed from left lateral view); (D) S. altus UCMZ 1980.1 (reversed from left lateral view); (E) Ornithomimus edmontonicus CMN 8632 (reversed from left lateral view); (F) O. edmontonicus (or Dromiceiomimus brevetertius) AMNH 5201 (reversed from left lateral view). Compare with Q. henanensis, HGM 41HIII0106 (Xu et al. 2011, figs. 3 and 8). Scale bars equal $5 \mathrm{~cm}$. 
Although Russell (1972) did not use any characters of the pubis to refer CMN 8902 to S. altus, Norell et al. (2001, character 178) and Choiniere et al. (2012, character 461) recognized that the pubic apron in avetheropods extends medially from either the middle of a cylindrical pubic shaft (state 0 ) or the anterior edge of a flattened pubic shaft (state 1). Among ornithomimids, only S. altus has been scored as displaying state 0 , in contrast to state 1 in G. bullatus, O. edmontonicus, R. evadens, and Sinornithomimus dongi (Norell et al. 2001; Choiniere et al. 2012; Sues and Averianov 2016; McFeeters et al. 2016). However, this character is not readily evaluable in previously described specimens of S. altus, due to the anteromedial surface of the pubic shaft being unpreserved (CMN 930) or embedded in a panel mount (AMNH 5339, UCMZ 1980.1). The presence of state 0 can be confirmed in CMN 8902 and AMNH 5355, the latter being another partial skeleton from the Dinosaur Provincial Park area referred to S. altus by Osborn (1917). However, the taxonomic identity of AMNH 5355 may also be uncertain, as many highly informative regions of the body are unknown (including the manus, pubic boot, and metatarsus). The tibia and tarsus of AMNH 5355 appear to lack the diagnostic characters of Qiupalong, but are heavily restored. Sues and Averianov (2016, character 461) scored the state of the connection between the pubic apron and pubic shaft in Q. henanensis as unknown. Although the published figures of HGM 41HIII-0106 do not permit assessment of the cross-sectional shape of the shaft, the pubic apron can be seen emerging from the middle of the medial side of the shaft, rather than the anterior edge (Xu et al. 2011, fig. 3b). Thus, the presence of state 0 in CMN 8902 may be equivocal in supporting the referral of this specimen to either Struthiomimus or Qiupalong. Aside from the pubis, the only other element known in both CMN 8902 and Q. henanensis (HGM 41HIII-0106) is the ilium. The ilia are incomplete in both specimens and do not display any characters recognized as diagnostic at lower taxonomic levels within Ornithomimidae.

Russell (1972) noted two characters in CMN 8902 that he considered diagnostic of S. altus: proportionately broad proximal caudal vertebrae, and a relatively robust forelimb. Neither character is directly evaluable in the known material of $Q$. henanensis (Xu et al. 2011). The width of the proximal caudal vertebrae is similarly greater than half of the centrum length in G. bullatus (Osmólska et al. 1972, table 2), suggesting that this character state may be plesiomorphic for derived ornithomimids and not an autapomorphy of $S$. altus. The character of a robust forelimb is retained in some modern diagnoses of Struthiomimus (Longrich 2008), and we cannot recognize any significant anatomical differences between the incomplete forelimbs of CMN 8902 and S. altus (UCMZ 1980.1). However, a robust humerus is also known in the Asian ornithomimid Anserimimus planinychus (Kobayashi and Barsbold 2006, fig. 6a). The known appendicular elements of Q. henanensis (pubis, tibia, and metatarsus) are relatively robust in comparison with other ornithomimids, suggesting the possibility of an overall robust morphology for that taxon. The scapulacoracoid of CMN 8902 resembles that of S. altus (UCMZ 1980.1) and O. edmontonicus (CMN 8632), but differs from the holotype of D. samueli (ROM 840) in having only a shallow depression on the coracoid marking the origin of M. coracobrachialis brevis instead of a deep pit bounded by a vertical crest. CMN 8902 differs from A. planinychus and G. bullatus in the position of the biceps tubercle close to the base of the posterior process of the coracoid (Kobayashi and Lü 2003).

More recent studies have noted diagnostic characters in the distal caudal vertebrae of North American ornithomimids (Longrich 2008; Zanno et al. 2013). Zanno et al. (2013, fig. 6) figured a distal caudal of CMN 8902 (as S. altus) to illustrate the absence of a grooved articulation between the prezygapophyses and the preceding centrum. This plesiomorphic condition is present throughout the caudal series and supports the distinction of CMN 8902 from Ornithomimus but does not confirm its referral to S. altus. Longrich (2008) identified three ornithomimid distal caudal morphologies in the Dinosaur Park Formation, which he interpreted as belonging to three distinct taxa: Ornithomimus sp., S. altus, and an unnamed new taxon of large ornithomimid. CMN 8902 includes an articulated series of 


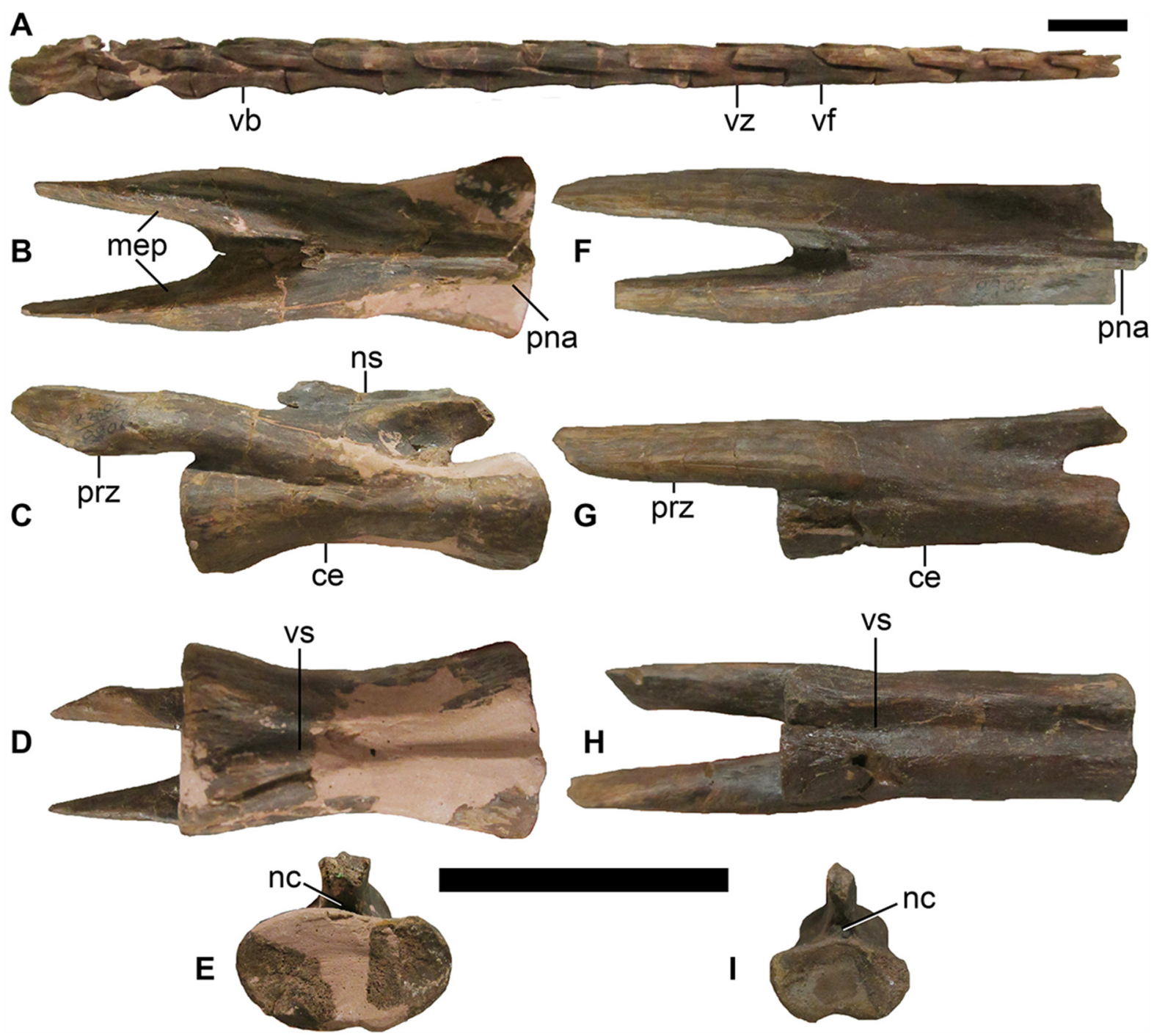

Fig. 5. Distal caudal vertebrae of Qiupalong sp., CMN 8902. (A) Articulated series of 13 distal caudal vertebrae in left lateral view. Distal caudal vertebra representing the more proximal morphology in (B) dorsal, (C) left lateral, (D) ventral, and (E) posterior views. Distal caudal vertebra representing the more distal morphology in (F) dorsal, $(\mathrm{G})$ right lateral (reversed), $(\mathrm{H})$ ventral, and (I) posterior views. ce, centrum; mep, medial expansion of prezygapophysis; nc, neural canal; ns, neural spine; pna, posterior extension of neural arch; prz, prezygapophysis; vb; vertebra depicted in B-E of this figure; vf; vertebra depicted in F-I of this figure; vs, ventral sulcus; vz; vertebra previously figured by Zanno et al. (2013, figs. $6 e, h, k$ ). Scale bars equal $5 \mathrm{~cm}$.

13 distal caudals documenting a transition from Longrich's "large ornithomimid" morphotype (hourglass-shaped centrum with an elliptical distal end, medially expanded prezygapophyses, and relatively wide posterior neural arch) proximally to a typical "S. altus" morphotype (resembling AMNH 5355 and AMNH 5385) distally (Fig. 5). The morphology of the caudal vertebrae of CMN 8902 thus refutes Longrich's assertion that no intermediate morphologies exist between the "large ornithomimid" material and other ornithomimid taxa in the Dinosaur Park Formation. It also calls into question the recognition of the "large ornithomimid" as a distinct taxon, although the non-vertebral material discussed by Longrich (2008) is still potentially diagnostic. Distal caudal vertebrae closely comparable with both the "large ornithomimid" and "S. altus" morphotypes are also present in G. bullatus (ROM 21704, cast of IGM 100/11), suggesting that these morphotypes are plesiomorphic 
for derived ornithomimids. The distal caudals are unknown in the holotype (CMN 930), and nearly unknown in the most completely described referred specimens (AMNH 5339, UCMZ 1980.1) of S. altus, making it difficult to confidently diagnose this species on the basis of distal caudal characters.

\section{UALVP 53595}

The complex interlocking suture between the astragalus and calcaneum, the shallowly excavated fibular facet on the calcaneum, and the presence of a transverse groove, rather than a median fossa, across the base of the ascending process of the astragalus are all consistent with an ornithomimid identity for UALVP 53595 and distinguish this specimen from oviraptorosaurs (Funston et al. 2015). The pit between the astragalus and calcaneum is uniquely shared by UALVP 53595 and Q. henanensis within Ornithomimidae. A distinct pit between the astragalus and calcaneum is not observed in any specimen of Ornithomimus, Rativates, or Struthiomimus, although in some articulated specimens this region is poorly preserved. In S. altus (AMNH 5385) and Ornithomimus velox (Claessens and Loewen 2015, fig. 7a), the lateral border of the astragalus has a shallow notch in the same position as the enclosed pit in UALVP 53595 and Q. henanensis. The relative height of the calcaneum in UALVP 53595 also suggests a closer relationship to Q. henanensis than to O. edmontonicus (CMN 8632) or S. altus (UCMZ 1980.1). The lack of fusion between the astragalus and the tibia differs from the holotype of $R$. evadens (ROM 1790).

\section{UALVP 52681}

Xu et al. $(2011,220)$ noted that Q. henanensis and the "large ornithomimid" unguals from the Belly River Group described by Longrich (2008) share the condition of ventrally curved pedal unguals, which they interpreted to potentially "suggest that there are derived ornithomimids with some primitive features, which are reversely evolved during the Late Cretaceous in Asia and North America, instead of the presence of primitive ornithomimids". However, Xu et al. (2011) did not comment on whether they considered this reversal to have evolved independently on each continent, or if they considered material described by Longrich (2008) to represent a potential sister taxon of Qiupalong. Averianov et al. (2017) clarified the definition of this character, noting that the angle between the proximal and distal parts of the ungual can be considered a separate character from the ventral concavity of the distal part. Averianov et al. (2017) considered the distal part to be ventrally concave in Q. henanensis, although this concavity is subtle, and the distal part to be angled ventrally relative to the proximal part (Xu et al. 2011, fig. 7). In the pedal unguals described by Longrich (2008), the distal part of the ungual is angled ventrally relative to the proximal part, but the ventral border of the distal part is straight. The distal parts of the unguals are not angled ventrally relative to the proximal parts in the type specimens of O. edmontonicus (CMN 8632), R. evadens (ROM 1790), and S. altus (CMN 930).

Isolated pedal unguals are among the most commonly collected and catalogued ornithomimid specimens in the Dinosaur Park Formation $(n>200)$, so the recognition of Qiupalong in this formation suggests that some previously collected unidentified or misidentified pedal unguals could also belong to this taxon. To this end, we examined isolated ornithomimid unguals from the Dinosaur Park Formation in the collections of the AMNH, CMN, ROM, TMP, and UALVP, and found at least one candidate, UALVP 52861, similar in morphology to Q. henanensis (HGM 41HIII-0106). This ungual has a ventrally angled distal portion with a straight ventral border but lacks the other features that characterize the "large ornithomimid" pedal ungual morphotype (Longrich 2008), and more closely resembles Q. henanensis (Xu et al. 2011, fig. 7) in having a more modest proximodorsal process and a very reduced flexor fossa and tubercle. Although the distal end is deflected slightly less ventrally in UALVP 52861 compared with HGM 41HIII-0106, the overall proportions and features sufficiently agree that if these two specimens were collected at the same locality, we would not hesitate to refer them to the same taxon. However, UALVP 52681 also conforms to the suite of characters listed by 
Longrich $(2008,990)$ as characterizing the pedal unguals of $S$. altus, which he described as "moderately curved". The preserved unguals of the type specimen of S. altus (CMN 930) are relatively straight, but a complete ungual III- 4 is not preserved in this specimen. The range of individual variation in ornithomimid pedal unguals is not yet well understood, and Cullen et al. (2013) were unable to confirm the results of Longrich (2008). As it is possible that UALVP 52681 falls within the normal range of variation for more than one ornithomimid taxon (e.g., Qiupalong and Struthiomimus), we do not regard this specimen as unequivocally referable to Qiupalong, although it does document the occurrence of a "Qiupalong-like" pedal ungual morphology in the Dinosaur Park Formation.

\section{Other potentially "Qiupalong-like" material}

The diagnosis of $Q$. henanensis given by Xu et al. $(2011,214)$ included one additional supposedly autapomorphic character, "a notch on the lateral surface of the medial posterior process of the proximal end of tibia". However, the figure of the tibia (Xu et al. 2011, fig. 4e) indicates the presence of this notch to be on the lateral surface of the lateral posterior process (fibular condyle), and no notch is evident on the lateral surface of the medial posterior process. TMP 1994.012.1010, an isolated left tibia of an ornithomimid from the Dinosaur Park Formation of Alberta, has a notched fibular condyle resembling the condition in $Q$. henanensis, with the portion posterior to the notch larger than the anterior portion (Fig. 6; Xu et al. 2011, fig. 4e). The presence of this character state in TMP 1994.012.1010 could be interpreted as additional support for the presence of Qiupalong in the Dinosaur Park Formation. However, most diagnostic ornithomimid skeletons from this formation have the state of this character as either unpreserved, ambiguous due to the quality of preservation or restoration, or inaccessible due to articulation with the other elements of the hind limb. Thus, it is uncertain whether this character, if phylogenetically significant, characterizes only Qiupalong or a more inclusive clade of derived ornithomimids.

\section{Taxonomic conclusions and significance}

CMN 8902 and UALVP 53595 possess derived characters or character combinations that are uniquely shared with Q. henanensis (Xu et al. 2011), and are distinct from other named ornithomimid taxa in the Belly River Group, when comparable. Previously noted similarities between CMN 8902 and

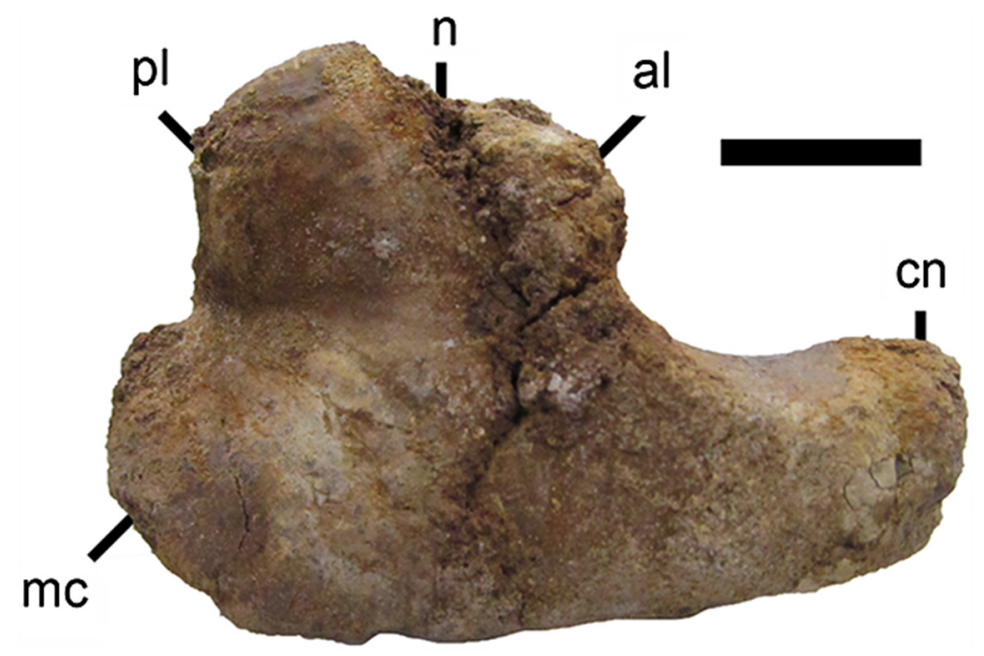

Fig. 6. Ornithomimidae indet., TMP 1994.012.1010, left tibia in proximal view. Compare with Qiupalong henanensis, HGM 41HIII-0106 (Xu et al. 2011, fig. 4). al, anterior lobe of lateral condyle; cn, cnemial crest; mc, medial condyle; $\mathrm{n}$, notch in lateral condyle; pl, posterior lobe of lateral condyle. Scale bar equals $2 \mathrm{~cm}$. 
S. altus appear to be plesiomorphic or homoplastic within Ornithomimidae. On account of the geographic and temporal separation of this material from Q. henanensis (Campanian of North America, versus probably Maastrichtian of Asia), it is unlikely that either Canadian specimen belongs to that species. Unfortunately, neither CMN 8902 nor UALVP 53595 is complete enough to determine whether all diagnostic characters of Q. henanensis listed by Xu et al. (2011) were present. Furthermore, there are no autapomorphic characters in this material that are absent in Q. henanensis. Therefore, we consider it most reasonable to refer CMN 8902 and UALVP 54595 to Qiupalong sp., as the first known North American representatives of this genus, although it is also possible that the discovery of additional material will support the naming of a new genus in the Qiupalong lineage. Observed differences between Qiupalong sp. and Q. henanensis are minor but appear to be closer to the probable plesiomorphic condition for North American ornithomimids in Qiupalong sp.

A similarity has long been noted between theropod assemblages in the Belly River Group of Alberta and various Upper Cretaceous localities in eastern Asia (Currie 1992), but relatively few taxa are shared at the generic level. A recent census of Canadian dinosaurs recognized only two dinosaur genera in the Belly River Group that are also present in Asia, the oviraptorosaurs Avimimus and Elmisaurus (Brown et al. 2015). More recently, Funston et al. (2016) considered the Dinosaur Park Formation elmisaurine material as generically distinct from Elmisaurus. The recognition of Qiupalong sp. in the Belly River Group thus adds significantly to the record of theropods with Asian affinities at the generic level in this group. Qiupalong sp. also represents the sixth ornithomimid taxon reported from the Dinosaur Park Formation. Although it may be suspected that not all of these taxa are distinct (e.g., Makovicky et al. 2004), the taxonomic diversity of non-macropredaceous theropods such as ornithomimosaurs and oviraptorosaurs in the Late Cretaceous may have been greater than generally appreciated, with at least three genera of Caenagnathidae present in the Dinosaur Park Formation (Funston et al. 2015), and seven genera of Oviraptoridae present in the Nanxiong Formation of southern China (Lü et al. 2016).

\section{Phylogenetic and palaeobiogeographic origins of Qiupalong}

The age of Q. henanensis was initially reported as "late Late Cretaceous" (Xu et al. 2011). Jiang et al. (2011) identified continuous deposition across the Cretaceous-Paleogene (K/Pg) boundary (66 Ma) at the top of the Qiupa Formation, which was previously thought to not have a conformable contact with the Paleocene Gaoyugou Formation (Xu et al. 2011). The exposed section of the Belly River Group in Dinosaur Provincial Park was deposited from approximately 76.5 to $74.8 \mathrm{Ma}$, in the Campanian stage (Eberth 2005). Ornithomimid material with diagnostic characters of Qiupalong may, therefore, occur up to approximately 10 million years earlier in North America than in Asia, although it is still not precisely known how much time is represented between the dinosaur-bearing beds of the Qiupa Formation and the K/Pg boundary.

The phylogenetic analysis by Xu et al. (2011) recovered Q. henanensis as the sister taxon of (S. altus + O. edmontonicus), based on two derived characters of the pubis: a large acute angle between the pubic shaft and boot (character 45: state 1), and the tip of the anterior extension of the pubic boot extending farther anteriorly than the anterior border of the pubic shaft (character 46: state 1). These characters are potentially correlated, in being related to a rotation of the pubic boot with respect to the shaft. Xu et al. (2011) scored both characters as unknown in S. altus, but the derived states can be confirmed in referred specimens of this species (AMNH 5339, UCMZ 1980.1). A single character supported the exclusion of $Q$. henanensis from the (S. altus + O. edmontonicus) clade: the presence in the latter of a pubic boot with a strongly convex ventrally expanded ventral border (character 35: state 0 ). Based on the distribution of taxa included in the phylogenetic analysis by Xu et al. (2011), Q. henanensis could be inferred to have diverged from the ancestor of the 
(S. altus + O. edmontonicus) clade prior to the migration of the latter into North America from Asia. However, ornithomimid specimens from the Kaiparowits and Hell Creek formations in the United States (DeCourten and Russell 1985; LACM 47520) show plesiomorphic characters in the pubis that are absent in $Q$. henanensis and the Canadian ornithomimids, including a distally recurved pubic shaft (Xu et al. 2011, character 44: state 0), suggesting that some North American ornithomimids diverged more basally than Qiupalong. Although the degree of convexity and ventral expansion of the ventral border of the pubic boot was cited to exclude Q. henanensis from the (S. altus + O. edmontonicus) clade, the expression of this character in Canadian ornithomimids is highly variable. This character is most highly developed in AMNH 5201 (Fig. 4F), referred to O. edmontonicus (Eberth et al. 2013) or Dromiceiomimus brevetertius (Russell 1972) but is much less developed in the potentially conspecific O. edmontonicus holotype CMN 8632 (Fig. 4E), which more closely resembles the condition in Q. henanensis.

Sues and Averianov (2016) recovered Q. henanensis as the sister taxon of the clade (A. planinychus + O. edmontonicus), with $S$. altus as the sister taxon of the former three taxa. The relationship between Q. henanensis and (A. planinychus + O. edmontonicus) was supported by the supposed absence of a pronounced flexor fossa on the ventral surface of the proximal end of the pedal unguals (Sues and Averianov 2016, character 567: state 0), regarded as occurring in Q. henanensis and O. edmontonicus (Sues and Averianov 2016; Averianov et al. 2017); the condition in A. planinychus has not been described. However, a pronounced flexor fossa can be observed in at least some pedal unguals of O. edmontonicus (CMN 8632, ROM 851), as well as in O. velox (CMN 12242, cast of YPM 542), so this character does not support a close relationship between Ornithomimus and Qiupalong. A sister taxon relationship between Anserimimus and Ornithomimus has been previously suggested primarily on the basis of manual characters (Bronowicz 2011), which are not preserved in Qiupalong. In the analysis by Sues and Averianov (2016), the "subequal" length of metatarsals II and IV in these taxa (character 559: state 0) is recovered as providing additional support for the (A. planinychus + O. edmontonicus) clade excluding Qiupalong. However, a comparison of published measurements of ornithomimid metatarsals (Parks 1933; Sternberg 1933; Osmólska et al. 1972; Russell 1972; Barsbold 1988; Xu et al. 2011; Claessens and Loewen 2015) suggests that the variation in this ratio is not split between two discrete character states, and just as much variation can occur between specimens of a single taxon or even between different authors' measurements of the same specimen. The metatarsal II/IV ratio derived from measurements of O. edmontonicus (CMN 8632) by Claessens and Loewen (2015, appendix 1) is indistinguishable from that of Q. henanensis, as measured by Xu et al. (2011, table 1).

A close relationship between Qiupalong and Ornithomimus may be supported by the presence of an approximately $\mathrm{T}$-shaped proximal end of the second metatarsal in medial or lateral view (Claessens and Loewen 2015, figs. $8 c-d$; Xu et al. 2011, figs. $6 d-e$ ). The proximal end of the second metatarsal has a simple subtriangular expansion that merges gradually with the posterior border of the metatarsal shaft in Archaeornithomimus asiaticus (Smith and Galton 1990, fig. 4b), Garudimimus brevipes (Kobayashi and Barsbold 2005, fig. 15d) R. evadens (McFeeters et al. 2016, fig. 10d), S. dongi (Kobayashi and Lü 2003, fig. 23b), and S. altus (Osborn 1917, fig. 11). In Q. henanensis (Xu et al. 2011, fig. 6d), Ornithomimus sp. (TMP 1995.110.1), and O. velox (Claessens and Loewen 2015, fig. 8c) the posterior expansion has a more pronounced ventral border distinct from the shaft, and the transition from the proximal expansion to the vertical posterior border of the shaft is abrupt. However, this condition of the second metatarsal is also present in a basal ornithomimosaur foot from the Lower Cretaceous of China (Shapiro et al. 2003, fig. 1f). Another character shared by Q. henanensis and some specimens of Ornithomimus is the laterally divergent distal end of metatarsal IV, which is separated by a gap from the distal end of metatarsal III (Claessens and Loewen 2015, figs. $4 f$ and $11 k$; Xu et al. 2011, fig. 6a). Parks (1933) originally noted this character in his diagnosis of 
"Struthiomimus ingens" (ROM 852), later synonymized with O. edmontonicus (Makovicky et al. 2004), although the type specimen of O. edmontonicus (CMN 8632) has the distal ends of metatarsals III and IV closely appressed (Claessens and Loewen 2015, fig. 11g). The distal end of metatarsal IV is also divergent from metatarsal III in Q. henanensis (Xu et al. 2011, fig. 6a) and O. velox (Claessens and Loewen 2015, fig. 4f). Claessens and Loewen (2015) considered the relatively short and robust metatarsus to be an autapomorphy of O. velox, but did not compare it to $Q$. henanensis, which has a very similarly proportioned metatarsus. It is possible that Qiupalong is nested phylogenetically within Ornithomimus, as the sister taxon of O. velox. The currently accepted monophyly of $O$. velox and O. edmontonicus is based solely on the relative lengths of the metacarpals (Claessens and Loewen 2015), which are not preserved in any specimen of Qiupalong.

The likely greater geological age of the Canadian Qiupalong sp. material in comparison with Q. henanensis and the reconsideration of characters bearing on the phylogenetic relationships of Qiupalong to other North American ornithomimids both support a North American origin for this genus. North American ornithomimids attained a high taxonomic and morphological diversity by the late Campanian (McFeeters et al. 2016; Serrano-Brañas et al. 2016). At least some characters previously considered diagnostic of $Q$. henanensis (combination of straight pubic shaft and reduced anterior extension of pubic boot, pit between astragalus and calcaneum) evolved prior to the dispersal of Qiupalong into Asia. A complex palaeobiogeographic history involving multiple dispersals between North America and Asia has been supported for a variety of other Late Cretaceous dinosaur clades, including hadrosaurids (Prieto-Márquez 2010), neoceratopsians (Xu et al. 2010), dromaeosaurids (Evans et al. 2013), and tyrannosaurids (Brusatte and Carr 2016). Loewen et al. (2013) proposed a relationship between falling sea levels at the end of the Campanian or the beginning of the Maastrichtian and the dispersal of several dinosaur clades (including tyrannosaurines, centrosaurines, and some hadrosaurid lineages) into Asia from North America, although Brusatte and Carr (2016) found it equally parsimonious that Tyrannosaurus dispersed into North America from Asia. The dispersal of a derived ornithomimid, Qiupalong, into Asia from North America may have occurred during this time as part of the same faunal interchange event and suggests a more complex history of ornithomimid dispersals in both directions across Beringia, comparable to the pattern previously proposed in other dinosaur clades.

\section{Institutional Abbreviations}

AMNH, American Museum of Natural History, New York, New York, USA; CMN, Canadian Museum of Nature, Ottawa, Ontario, Canada; HGM, Henan Geological Museum, Zhengzhou, Henan, China; IGM, Mongolian Institute of Geology, Ulaanbaatar, Mongolia; LACM, Los Angeles County Museum, Los Angeles, California, USA; ROM, Royal Ontario Museum, Toronto, Ontario, Canada; TMP, Royal Tyrrell Museum of Palaeontology, Drumheller, Alberta, Canada; UALVP, University of Alberta Laboratory for Vertebrate Palaeontology, Edmonton, Alberta, Canada; UCMZ, University of Calgary Museum of Zoology, Calgary, Alberta, Canada; YPM, Yale Peabody Museum of Natural History, New Haven, Connecticut, USA.

\section{Acknowledgements}

We thank C Mehling and M Norell at the AMNH; M Currie, J Mallon, and K Shepherd at the CMN; D Evans, B Iwama, and K Seymour at the ROM; D Brinkman, G Housego, J Northover, and B Strilisky at the TMP; E Koppelhus and I Macdonald at the UALVP; and W Fitch and A Russell at the UCMZ for assistance during collection visits. We thank D Evans, C Serrano-Brañas, and an anonymous reviewer for their reviews of the manuscript. This research was funded by a grant from the Dinosaur Research Institute. 


\section{Author contributions}

Conceived and designed the study: BM, MJR, CS-A. Performed the experiments/collected the data: BM. Analyzed and interpreted the data: BM. Contributed resources: PJC. Drafted or revised the manuscript: BM, MJR, CS-A, PJC.

\section{Competing interests}

MJR is currently serving as a Subject Editor for FACETS, but was not involved in review or editorial decisions regarding this manuscript.

\section{Data accessibility statement}

All relevant data are within the paper.

\section{References}

Averianov AO, Sues H-D, Dyke G, and Bayshashov B. 2017. Hind limb bones of an ornithomimid dinosaur from the Upper Cretaceous Bostobe Formation, northeastern Aral Sea region, Kazakhstan. Palaeoworld, 26: 194-201. doi:10.1016/j.palwor.2016.01.003.

Barsbold R. 1976. [On the evolution and systematics of the late Mesozoic dinosaurs]. Sovmestnaia Sovetsko-Mongol'skaia Paleontologicheskaia Ekspeditsiia Trudy, 3: 68-75. [Russian with English summary]

Barsbold R. 1988. A new Late Cretaceous ornithomimid from the Mongolia People's Republic. Paleontological Journal, 1988: 122-125.

Bronowicz R. 2011. New material of a derived ornithomimosaur from the Upper Cretaceous Nemegt Formation of Mongolia. Acta Palaeontologica Polonica, 56: 477-488. doi:10.4202/ app.2009.1123.

Brown CM, Ryan MJ, and Evans DC. 2015. A census of Canadian dinosaurs: more than a century of discovery. In All animals are interesting: a Festschrift in Honour of Anthony P. Russell. Edited by ORP Bininda-Emonds, GL Powell, HA Jamniczky, AM Bauer, and J Theodor. BIS Verlag, Oldenburg, Germany. pp. 151-209.

Brusatte SL, and Carr TD. 2016. The phylogeny and evolutionary history of tyrannosauroid dinosaurs. Scientific Reports, 6: 1-8. doi:10.1038/srep20252.

Choiniere JN, Forster CA, and de Klerk WJ. 2012. New information on Nqwebasaurus thwazi, a coelurosaurian theropod from the Early Cretaceous Kirkwood Formation in South Africa. Journal of African Earth Sciences, 71-72: 1-17. doi:10.1016/j.jafrearsci.2012.05.005.

Claessens LPAM, and Loewen MA. 2015. A redescription of Ornithomimus velox Marsh, 1890 (Dinosauria, Theropoda). Journal of Vertebrate Paleontology, 36: 1-15. doi:10.1080/ 02724634.2015.1034593.

Cullen TM, Ryan MJ, Schröder-Adams C, Currie PJ, and Kobayashi Y. 2013. An ornithomimid (Dinosauria) bonebed from the Late Cretaceous of Alberta, with implications for the behavior, classification, and stratigraphy of North American ornithomimids. PLoS ONE, 8: 1-9. doi:10.1371/journal. pone.0058853.

Currie PJ. 1992. Saurischian dinosaurs of the Late Cretaceous of Asia and North America. In Aspects of Nonmarine Cretaceous Geology, Proceedings of the First International Symposium of IGCP 245 
Nonmarine Cretaceous Correlations, Urumqi, China, 1987. Edited by NJ Mateer and PJ Chen. Ocean Press, Beijing, China. pp. 237-249.

Currie PJ, and Koppelhus EB. 2015. The significance of the theropod collections of the Royal Tyrrell Museum of Palaeontology to our understanding of Late Cretaceous theropod diversity. Canadian Journal of Earth Sciences, 52: 620-629. doi:10.1139/cjes-2014-0173.

DeCourten FL, and Russell DA. 1985. A specimen of Ornithomimus velox (Theropoda, Ornithomimidae) from the terminal Cretaceous Kaiparowits Formation of southern Utah. Journal of Paleontology, 59: 1091-1099.

Eberth DA. 2005. The geology. In Dinosaur provincial park: a spectacular ancient ecosystem revealed. Edited by PJ Currie and EB Koppelhus. Indiana University Press, Bloomington, Indiana. pp. 54-82.

Eberth DA, and Hamblin AP. 1993. Tectonic, stratigraphic, and sedimentologic significance of a regional discontinuity in the upper Judith River Group (Belly River wedge) of southern Alberta, Saskatchewan, and northern Montana. Canadian Journal of Earth Sciences, 30: 174-200. doi:10.1139/e93-016.

Eberth DA, Evans DC, Brinkman DB, Therrien F, Tanke DH, and Russell LS. 2013. Dinosaur biostratigraphy of the Edmonton Group (Upper Cretaceous), Alberta, Canada: evidence for climate influence. Canadian Journal of Earth Sciences, 50: 701-726. doi:10.1139/cjes-2012-0185.

Evans DC, Larson DW, and Currie PJ. 2013. A new dromaeosaurid (Dinosauria: Theropoda) with Asian affinities from the latest Cretaceous of North America. Naturwissenschaften, 100: 1041-1049. PMID:24248432. doi:10.1007/s00114-013-1107-5.

Funston GF, Persons WS, Bradley GJ, and Currie PJ. 2015. New material of the large-bodied caenagnathid Caenagnathus collinsi from the Dinosaur Park Formation of Alberta, Canada. Cretaceous Research, 54: 179-187. doi:10.1016/j.cretres.2014.12.002.

Funston GF, Currie PJ, and Burns ME. 2016. New elmisaurine specimens from North America and their relationship to the Mongolian Elmisaurus rarus. Acta Palaeontologica Polonica, 61: 159-173. doi:10.4202/app.00129.2014.

Gilmore CW. 1933. On the dinosaurian fauna of the Iren Dabasu Formation. American Museum of Natural History Bulletin, 67: 23-78.

Ji Q, Norell MA, Makovicky PJ, Gao K-Q, Ji S, and Yuan C. 2003. An early ostrich dinosaur and implications for ornithomimosaur phylogeny. American Museum Novitates, 3420: 1-19. doi:10.1206/0003-0082(2003)420<0001:AEODAI>2.0.CO;2.

Jiang XJ, Liu YQ, Ji SA, Zhang XL, Xu L, Jia SH, et al. 2011. Dinosaur-bearing strata and K/T boundary in the Luanchuan-Tantou Basin of western Henan Province, China. Science China Earth Sciences, 54: 1149-1155. doi:10.1007/s11430-011-4186-1.

Kobayashi Y, and Barsbold R. 2004. Phylogeny of Ornithomimosauria and its paleobiogeographic implications. In Proceedings of the 19th International Congress of Zoology, China Zoological Society, Beijing, China, 23-27 August 2004. pp. 50-52.

Kobayashi Y, and Barsbold R. 2005. Reexamination of a primitive ornithomimosaur, Garudimimus brevipes Barsbold, 1981 (Dinosauria: Theropoda), from the Late Cretaceous of Mongolia. Canadian Journal of Earth Sciences, 42: 1501-1521. doi:10.1139/e05-044. 
Kobayashi Y, and Barsbold R. 2006. Ornithomimids from the Nemegt Formation of Mongolia. Journal of the Paleontological Society of Korea, 22: 195-207.

Kobayashi Y, and Lü J-C. 2003. A new ornithomimid dinosaur with gregarious habits from the Late Cretaceous of China. Acta Palaeontologica Polonica, 48: 235-259.

Lambe LM. 1902. New genera and species from the Belly River Series (mid-Cretaceous). Geological Survey of Canada, Contributions to Canadian Paleontology, 3: 25-81.

Loewen MA, Irmis RB, Sertich JJW, Currie PJ, and Sampson SD. 2013. Tyrant dinosaur evolution tracks the rise and fall of Late Cretaceous oceans. PLoS ONE, 8: e79420. doi:10.1371/journal. pone.0079420.

Longrich NR. 2008. A new, large ornithomimid from the Cretaceous Dinosaur Park Formation of Alberta, Canada: implications for the study of dissociated dinosaur remains. Palaeontology, 51: 983-997. doi:10.1111/j.1475-4983.2008.00791.x.

Lü J, Chen R, Brusatte SL, Zhu Y, and Shen C. 2016. A Late Cretaceous diversification of Asian oviraptorid dinosaurs: evidence from a new species preserved in an unusual posture. Scientific Reports, 6: 1-12. doi:10.1038/srep35780.

Makovicky PJ, Kobayashi Y, and Currie PJ. 2004. Ornithomimosauria. In The Dinosauria. 2nd Edition. Edited by DB Weishampel, P Dodson, and H Osmólska. University of California Press, Berkeley, California. pp. 137-150.

Mallon JC, and Evans DC. 2014. Taphonomy and habitat preference of North American pachycephalosaurids (Dinosauria, Ornithischia). Lethaia, 47: 567-578. doi:10.1111/let.12082.

Marsh OC. 1882. Classification of the Dinosauria. American Journal of Science, 23: 81-86. doi:10.2475/ajs.s3-23.133.81.

Marsh OC. 1890. Description of new dinosaurian reptiles. American Journal of Science, 39: 81-86. doi:10.2475/ajs.s3-39.229.81.

McFeeters B, Ryan MJ, Schröder-Adams C, and Cullen TM. 2016. A new ornithomimid theropod from the Dinosaur Park Formation of Alberta, Canada. Journal of Vertebrate Paleontology, 36: 1-20. doi:10.1080/02724634.2016.1221415.

Norell MA, Clark JM, and Makovicky PJ. 2001. Phylogenetic relationships among coelurosaurian theropods. In New perspectives on the origins and early evolution of birds: Proceedings of the International Symposium in Honor of John H. Ostrom. Edited by J Gauthier and LF Gall. Yale University, New Haven, Connecticut. pp. 49-67.

Osborn HF. 1917. Skeletal adaptations of Ornitholestes, Struthiomimus, Tyrannosaurus. Bulletin of the American Museum of Natural History, 35: 733-771.

Osmólska H, Roniewicz E, and Barsbold R. 1972. A new dinosaur, Gallimimus bullatus n. gen., n. sp. (Ornithomimidae) from the Upper Cretaceous of Mongolia. Palaeontologia Polonica, 27: 103-143.

Parks WA. 1928. Struthiomimus samueli, a new species of Ornithomimidae from the Belly River Formation of Alberta. University of Toronto Studies, Geological Series, 26: 1-24. 
Parks WA. 1933. New species of dinosaurs and turtles from the Upper Cretaceous formations of Alberta. University of Toronto Studies, Geological Series, 34: 1-33.

Prieto-Márquez A. 2010. Global historical biogeography of hadrosaurid dinosaurs. Zoological Journal of the Linnean Society, 159: 503-525. doi:10.1111/j.1096-3642.2010.00642.x.

Russell DA. 1972. Ostrich dinosaurs from the Late Cretaceous of western Canada. Canadian Journal of Earth Sciences, 9: 375-402. doi:10.1139/e72-031.

Serrano-Brañas CI, Torres-Rodríguez E, Reyes-Luna PC, González-Ramírez I, and González-León C. 2016. A new ornithomimid dinosaur from the Upper Cretaceous Packard Shale formation (Cabullona Group) Sonora, México. Cretaceous Research, 58: 49-62. doi:10.1016/j.cretres.2015.08.013.

Shapiro MD, You H, Shubin NH, Luo Z, and Downs JP. 2003. A large ornithomimid pes from the Lower Cretaceous of the Mazongshan area, northern Gansu Province, People's Republic of China. Journal of Vertebrate Paleontology, 23: 695-698. doi:10.1671/A1088.

Smith D, and Galton P. 1990. Osteology of Archaeornithomimus asiaticus (Upper Cretaceous, Iren Dabasu Formation, People's Republic of China). Journal of Vertebrate Paleontology, 10: 255-265. doi:10.1080/02724634.1990.10011811.

Sues H-D, and Averianov A. 2016. Ornithomimidae (Dinosauria: Theropoda) from the Bissekty Formation (Upper Cretaceous: Turonian) of Uzbekistan. Cretaceous Research, 57: 90-110. doi:10.1016/j.cretres.2015.07.012.

Sternberg CM. 1933. A new Ornithomimus with complete abdominal cuirass. Canadian Field Naturalist, 57: 79-83.

Xu X, Wang K, Zhao X, Sullivan C, and Chen S. 2010. A new leptoceratopsid (Ornithischia: Ceratopsia) from the Upper Cretaceous of Shandong, China and its implications for neoceratopsian evolution. PLoS ONE, 5: 1-14. doi:10.1371/journal.pone.0013835.

Xu L, Kobayashi Y, Lü J, Lee Y-N, Liu Y, Tanaka K, et al. 2011. A new ornithomimid dinosaur with North American affinities from the Late Cretaceous Qiupa Formation in Henan Province of China. Cretaceous Research, 32: 213-222. doi:10.1016/j.cretres.2010.12.004.

Zanno LE, Loewen MA, Farke AA, Kim G-S, Claessens LPAM, and McGarrity CT. 2013. Late Cretaceous theropod dinosaurs of southern Utah. In At the top of the grand staircase: the Late Cretaceous of Southern Utah. Edited by AL Titus and MA Loewen. Indiana University Press, Bloomington, Indiana. pp. 504-525. 